\title{
Mapping the multiplicity of the self
}

\author{
Commentary on Hermans" "The construction of a Personal Position Repertoire: Method \\ and Practice" \\ Miguel Gonçalves (University of Minho, Portugal) \\ $\&$ \\ João Salgado (ISMAI, Portugal) \\ Culture and Psychology (2001), 3, 367-378
}

There is no psychology, there is only biography and auto-biography.

Thomas Szazs

We have been very interested in Hubert Hermans' work and it's a pleasure for us to have the opportunity to reflect on his theoretical and methodological proposals. If every utterance is an answer to a question, as Bakhtin (1963/1984) argued, the following one seems to be central to Hermans and his collaborators: how do we create meaning in our lives? In his efforts to answer this question, Hermans has been developing a theoretical system, based on the valuation theory and the self-confrontation method (SCM) (see Hermans \& Hermans-Jensen, 1995), in which the self is conceived as a narrative process.

But Hermans and Kempen (1993) go beyond this. They not only recognize the linguistic basis of self-understanding; they also insist on the relational features of language itself. Anchored on Bakhtin's work, they invite us to appreciate of self-narratives as dialogues between different narrative positions. That has created one of the most promising ways to develop a dynamic perspective about selfhood. As Valsiner (2000) recently asserts, 
we need a new vocabulary to surpass the old static conceptions of self, and the "Nijmegen tradition of dialogical self' [is] the most promising conceptualization system" (p.4).

Hermans and collaborators (see Hermans, 1996; Hermans \& Hermans-Jensen, 1995; Hermans \& Kempen, 1993) lead us towards the idea of a "spatialized" self, with different voices clustered around different I-positions. This process of constructing integration through dialogue is one of the most interesting and important characteristics of their work and is clearly visible in the present article. Moreover, Hermans also clarifies how personal meaning is anchored in social voices. These two aspects of his work - the construction of integration through dialogue and the contributions from other characters that are present in the social (even imaginary) space of the person — are, in our view, very important for the understanding of the self and the transformations of meaning that take place in our lives and in psychotherapy. Furthermore, the relationship that is presupposed between multiplicity and social influence of the internal voices allows us to overcome the conception of a self isolated from the social world, what some scholars have called the selfcontained self (e.g., Sampson, 1993; Stlororow \& Atwood, 1992). These aspects influenced us very much in our clinical practice, and we look forward with curiosity to the developments they will inspire.

Now Hermans offers us a new challenge: the Personal Position Repertoire (PPR), which is a procedure for mapping the dialogical self. We could say that, after the SCM, this is also a methodological tool that represents an effort to study the dialogical processes of the self. In this article, for the purpose of illustrating this method, Hermans uses several clinical and case studies, which make this dialogue between theory and practice clear and particularly interesting.

In this commentary, we will try to detach ourselves from our adherence to Hermans' ideas in order to create a counter-voice. As Bakhtin argued, when our vision is 
supplemented with the vision of others, a "surplus of seeing" occurs, which can bring us a more comprehensive perspective (see Holquist, 1990).

\section{The personal organization of the dialogical self}

The PPR is a tool devised to study the organization of the dialogical self. Its fundamental advantage is that it allows us to get in touch with the different narrative positions available to the person, the repertory of potential voices.

We suggest that in this method we can find two central and new assumptions of Hermans' work:

- the narrative positions can be elicited through an articulation between external and internal positions;

- the prominence is a central dimension of dialogical organization.

At first sight, the separation between internal and external positions could appear to be a return to the old Cartesian divisions. However, the PPR is constructed in such a way that it is not possible to completely dissociate the internal and the external, because they function as coordinated pairs. This can be related to one of Bakhtin's (1979/1986) central ideas: the creation of meaning and the creation of self involves a relation between the I and the Other, or between a center and a periphery (Holquist, 1990). In a communicative act, the speaker always addresses an audience. In this way, every act of self-understanding is a relational act by which the person defines his or her position towards others. In practical terms, what Hermans is doing can be described as a coordination between self-referential terms and different kinds of audiences and contexts.

The second assumption is related to the "prominence", which in this method means the kind of relation each internal position has with the external positions ("the extent of coming forward"). This gives an opportunity to appreciate the audience of a particular position, allowing the study of the relationship between different voices. It is possible, for 
example, to find out that some positions are addressed only to a small audience or, on the contrary, that the audience of some particular voice contains a wide rage of characters. And, fundamentally, it also creates an opportunity to explore the dialogues that are going on around one specific position.

But what does prominence mean in this context? As Hermans says, the prominence score can have different meanings (e.g., a low prominence of an internal position can mean that it is not an important position, that it is an important position but restricted to some particular contexts, or that is a suppressed position). So, prominence it is not a direct index of power or dominance.

In our view, if the target is the organization of the dialogical self, we also would be interested in developing a way of getting in touch with the power of each position. As Hermans and Kempen (1993) have recognized, power is related with dialogue. More specifically, they have stated that some positions can dominate others, which means that that position has a more powerful place than the dominated ones. The results of our research suggest that this can have two kinds of outcomes: on the one hand, the dominant position may suppress some potential voices and even inhibit the movement to other forms of meaning-making; and on the other hand, it can be an organizing and integrating tendency, necessary to positioning ourselves in the here-and-now (Salgado \& Gonçalves, 2000).

We tend to consider power and dominance as especially important dimensions of the personal organization of multivocality, as Nancy's case demonstrates: the most relevant position was the "child", because that voice was dominating her daily life. The same phenomenon occurs with many psychotherapy clients: they feel that their lives are dominated by specific voices, sometimes even absurd or illogical, but powerful nevertheless. Unfortunately, the prominence index does not give us a clear indication of the power dimension of dialogical relationships. However, Hermans also shows that this can be 
compensated with a simple procedure: asking the person to write a diary where a careful analysis of the power of each position in daily life is developed.

\section{The process of assessment}

Every method of research and every process of assessment are ways of producing a specific reality. PPR is not an exception, which leads us to a careful examination of the process of assessment in order to clarify the data.

In our view, the most problematic implicit assumption of PPR is the cross-situational prominence of each voice. For instance, the presence of an internal position (e.g., "I as a psychologist") related to one particular external position (e.g., "my father") could bear different meanings, depending on the context (e.g., my work or my family), or even depending on the specific interaction in the same context. This is related to an important and difficult problem for any methodology devised to assess the dialogical self: from what position is the person talking in each moment? Without an answer to this question, it is difficult to know what kinds of results we are obtaining. It is difficult to say, because while the person is rating the matrix, it is assumed that a dialogical process is still present. But what kind of position is the person assuming in that particular moment in time? Is the person assuming the internal position under evaluation in the rating process? Or is the person assuming a different position from which is appreciating the one under evaluation. For instance, it could be that one of us, while evaluating the position "me as psychologist", appreciates his experience as he usually does when he assumes that role. But it is also possible that, while rating the same position, one assumes a slightly different position, for instance, "me as optimistic", from which he evaluates what happens in his experience as psychologist.

We suspect that a possible hidden assumption is present: that we can assume a metaposition that evaluates the other ones - a kind of neutral and cross-situational position, from 
which the person rates the prominence. But, what kind of information does a person have to have in mind during this rating? A particular situation, a selective view of how the person has been behaving, what the person has been thinking about himself or herself in the last week, what the person believes others think about her or him? And aren't all the options important and potentially generative of different informative matrices? How can we decide to choose between the different possibilities? We think that PPR is an interesting acting performance, but maybe we are losing the best part of it: what the person is doing while rating the matrix, the dialogues that are going on. It could be like predicting the weather using a unique photo of the sky, losing the changes that are continuously occurring.

Given that we believe that the person answering the PPR needs to arrive at some kind of meta-position during the ratings (prominence and affects), reification could be an undesirable outcome, leading the person to take the results as the way she or he really is.

It is true that Hermans (in this issue) alerts us to the fact that, despite the similarity between the positions and traditional traits, these are not traits, but we do not see how he avoids the subjects transforming their responses into something similar to traits. Hermans seems very concerned with avoiding reification and he refers to this several times in the article. One important argument he makes is that positions (internal and external) are not reflections of the way a person is but they "function as I-positions" (p. 10). But again, how can people take this into account when looking at the final results? The theory allows the psychologist to avoid reification of the meaning that emerges in the PPR, but how can we avoid rigidification of meaning from the participants? If we use PPR as a general method we face the risk of suggesting to clients that it gives a true reflection of the person, instead of particular constellations of I-positions in an ever-changing self-space.

Of course, we are not denying that PPR is an interesting exercise to be used in psychotherapy, especially if we collect more information regarding the multifacetedness and multivocality (Hermans, 1996) of the self. Hermans convincingly shows that PPR can be a starting point for a change in the dialogue between the psychologist and the person. It 
has some additional features that can be further explored. For example, it could be very interesting to know what the relevant external voices suggest in relation to several problematic issues and how the available internal ones react to these.

\section{Issues about expertise and psychotherapy}

One other problem that concerns us in the SCM and now in the PPR is the differential power they may imply between psychologist and client. Hermans insists (and he does this in other texts as well, see for instance Hermans and Hermans-Jansen, 1995) that the final meaning is negotiated between psychologists and clients: "the participants... [are seen] as experts of the meaning they give to events in their own lives... [and] the psychologist is seen as an expert in theory" (p.19). It is clear that these procedures are more collaborative than the traditional ones used by personality psychologists (e.g., personality questionnaires). We wonder, however, about the way the theory shapes the knowledge of the participants and even changes the meaning of their experience. One can argue that when a person asks for counseling or psychotherapy, in one way or another, they feel the need to create some changes in the meaning of their lives. However, if the psychotherapist imposes a specific way of interpreting the person, this can have a negative outcome: a "dialogical monologization". In this way, the content will be about dialogue, but the process represents a monologic temptation. Therefore, if the problem is not only the modification of meaning, but also the empowerment of the client, a question remains for all of us: how to respect the expertise of the person?

In the majority of narrative therapies (see for instance, McNamee \& Gergen, 1992; Hoyt, 1998), there is a central concern about the issue of power differences between psychologist and client, and some suggestions have been made for helping the clinician to become more an expert in the process of therapy, than in the product of it (Anderson $\&$ Levin, 1998). In the specific case of PPR, we wonder if the desired outcomes would not be possible in a more negotiated way. For instance, we could try to find different voices and 
regularities between different positions through a more narrative (e.g., narrative interview, reflection with the therapist) and less paradigmatic way (e.g., Pearson's correlation, list of pre-given affects, likert scale of the affects). In our view, that would be more empowering to the client than to rely in processes (such as the above mentioned) that only the psychologist has expertise over.

An illustration of this problem can be found in this article. Discussing the affective connotations of the valuations, Hermans proposes that the collaboration between the psychologist and the client is evident, since the client offers the content of the valuations and the psychologist helps them to understand its meaning. Accordingly, "affective meaning of the valuations is more the product of the methodological expertise of the psychologist" (p.20). But how can the position of the participant as an author remain central, since, as he writes, "when we know more about the particular connotation represented by a particular valuation, we know more about the valuation itself, which also implies that the affective meaning of a valuation cannot be separated from it." (p.23). If the "particular connotation" is, at least in part, given by the expertise of the psychologist, couldn't this limit the ability of the client to generate meaning? Wouldn't it be possible that this expertise of the psychologist reduces the ability of the participant to author their own lives, given that it's not possible to separate the content of the valuation (resulting from the client) and the emotional meaning (resulting from the expertise of the psychologist)? Couldn't the last one be imposed on the former?

Of course, we are not suggesting here that PPR can not be useful in psychotherapy and certainly it is an invaluable tool for certain types of research. However, we believe that our clients will benefit if we try to use processes in which they are experts. In this way, instead of attributing the power to the techniques, they can attribute the power to themselves and to the therapeutic conversation.

We will illustrate our position, using Nancy as an example. The main outcome of PPR was the identification of a problematic facet: "the child position". Interestingly, this 
conclusion was not based on the correlation, but in a narrative process: Nancy kept a diary and discussed it with the psychotherapist. As the process developed, an interesting reaction happened, in which Nancy detached herself from "the child". The costs of this childposition became transparent and this opened the door for the emergence of a counter-story. The "independent" seemed a very good candidate for organizing this new story of herself. This created the possibility for the therapist to work further in contrasting the "old" (Nancy dominated by the "child") and the "new" (Nancy giving a voice to the "independent") stories $^{1}$. We ask ourselves if the PPR computations were really so important in arriving at this point of the therapeutic process.

In our clinical practice we have been working with the meaning of different facets of the self in relation to a particular problem. This is inspired by the narrative therapy of White and Epston (1990), since they emphasize the way in which problems and counterstories are socially supported. After the client identifies several facets, we try to anchor them historically (in the life of the client) and socially, trying to find what characters in their life-stories support or oppose each facet ${ }^{2}$. For instance, we would be interested in knowing how a specific facet makes sense in a particular relationship, or the way that facet is silenced in another relationship. In this process of anchoring the facets we also try to detail specific episodes in which each facet is present or activated. This is a way we frequently use, to deal with the multiplicity (of facets or positions) and to relate these to the social influences that shape them. From a standpoint like this, which we believe is congruent with Hermans' theory on the dialogical self, an almost infinite number of questions can be posed to understand more about the meaning of each position.

We do not completely agree with the claim from Szazs that we quoted in the beginning of this commentary, but we feel that, psychology has been creating devices to

\footnotetext{
${ }^{1}$ Curiously enough this account of the process reminds us the way narrative therapist operates (see White \& Epston, 1990).

${ }^{2}$ Of course, opposition and support are not the only relationships that can be meaningful to the client.
} 
evaluate, assess and control their subjects for many years. Some are more authoritarian (like the former projective tests that discover "truths" even "against" the clients), some are more collaborative (like the PPR and the SCM). Hermans recognizes in his dialogical personal style that PPR is not meant to be the only procedure to study the dialogical self. However, probably it is also the time to explore the benefits of biography and autobiography. It could be a fantastic challenge: to explore the theoretical field that Hermans has created — dialogical self, multivocality, intersubjective change, and so on through narrative-based strategies, like biographies and auto-biographies.

\section{Generative questions}

There is a striking feature in Hermans' article we have yet mentioned: the clear way he shows how the problems we face in psychotherapy can be conceived as oppositions between different narrative modes. Conflict and pain are drawn in a developing drama where voices fight for a place in people's lives. Moreover, he also illustrates how movement and dialogue between different voices has a potential positive effect. The psychotherapeutic work unfortunately is not further detailed, but it seems tremendously dialogical and narrative-based. We conclude that even if some features of it are troublesome, it has some strongly positive aspects, namely:

- it may facillitate the development of a range of potential narrative positions;

- it may feed the development of dialogical processes by encouraging the person to tell her/his story from a different position.

These two features have a significant contribution towards a more dynamic and dialogical way of doing psychotherapy. Moreover, they raise two different kinds of generative questions: the problem of personal organization and complexity of the dialogical self, and the problem of improving our ability to help those who ask for help in psychotherapy. 
The first problem is related to several specific questions. For instance, what kind of dialogical organization underlies the problems we deal with in psychotherapy? Is the person dominated by a specific voice that silences and monologizes others? Or is the problem linked to voice dissociation (see Hermans \& Gonçalves, 2000)?

If we learn more about specific types of dialogical organization, we will be able to better understand the persons seek for psychotherapy. But we will also need to clarify what can be helpful and empowering for that particular person, living in a particular situation. Will the person benefit from an effort to give voice to a specific position? Are there occasions that require a restriction in the dialogue with one position? Why, how and when?

Different authors (e.g., Elliot \& Greenberg, 1997; Hermans, 1997; Honos-Webb \& Stiles, 1998; Stiles, 1997) have made some interesting contributions to answer these questions, in a fascinating dialogue between "old" voices and "new" voices. In this field, Valsiner also (2000) has made an extremely promising proposal of classification between different developments of dialogical relationships that match Hermans' theory. And this is only one example of many exciting developments we can expect to find in the theoretical field of the dialogical self.

We look forward, with excitement and curiosity, to the new paths these dialogues will create.

\section{Authors note}

We thank Scott McIntyre and Ned Norris for their editorial comments.

Correspondence concerning this article should be addressed to Miguel Gonçalves, Departamento de Psicologia, Universidade do Minho, 4700 Braga, Portugal.

E-mail: mgoncalves@iep.uminho,pt 


\section{References}

Anderson, H \& Levin, S. B. (1998). Generative conversations: A postmodern approach to conceptualizing and working with human systems. In M. F. Hoyt (Ed.), The handbook of constructive therapies: Innovative approaches from leading practitioners (pp. 46-67). San Francisco: Jossey-Bass.

Bakhtine, M. M. (1984). Problems of Dostoevky's poetics. Minneapolis: University of Minnesota Press. (originally published in 1963).

Bakhtine, M. M. (1986). Speech genres and other late essays. Austin: University of Texas Press. (originally published in 1979).

Elliott, R., \& Greenberg, L. (1997). Multiple voices in process-experiential therapy: dialogues between aspects of the self. Journal of Psychotherapy Integration, 7, 225240.

Hermans, H. J. M., \& Gonçalves, M. (1999). Self-knowledge and self-complexity: A dialogical view. Constructivism in the Human Sciences, 4, 178-197.

Hermans, H. J. M. (1996). Voicing the self: From information processing to dialogical interchange. Psychological Bulletin, 119, 31-50.

Hermans, H. J. M. (1997). Dissociation as disorganised self-narrative. Tension between splitting and integration. Journal of Psychotherapy Integration, 7, 213-224.

Hermans, H. J. M., \& Hermans-Jansen, E. (1995). Self-narratives: The construction of meaning in psychotherapy. New York: Guilford.

Hermans, H. J. M., \& Kempen, H. J. G. (1993). The dialogical self: Meaning as movement. San Diego: Academic Press.

Holquist, M. (1990). Dialogism: Bakhtin and his world. London: Routledge.

Honos-Webb, L., \& Stiles, W. B. (1998). Reformulation of assimilation analysis in terms of voices. Psychotherapy, 35, 23-33. 
M. F. Hoyt (Ed.) (1998), The handbook of constructive therapies: Innovative approaches from leading practitioners. San Francisco: Jossey-Bass.

S. McNamee \& K. J. Gergen (1992) (Eds.), Therapy as a social construction. London: Sage.

Salgado, J., \& Gonçalves, M. (2000). After self-deception: Exploring the dialogical unconscious. Paper presented at the First International Conference on the Dialogical Self, 23-26 of June, Nijmegen, The Netherlands.

Sampson, E. E. (1993). Celebrating the other: A dialogic account of human nature. Boulder, CO: Westview Press.

Stiles, W. B. (1997). Multiple voices in psychotherapy clients. Journal of Psychotherapy Integration, 7, 177-180.

Stlororow, R. D. \& Atwood, G. E. (1992) Context of being: The intersubjective foundations of psychological life. New Jersey: Analytic Press.

Valsiner, J. (2000). Making meaning out of mind: self-less and self-ful dialogicality. Paper presented at the First International Conference on the Dialogical Self, 23-26 of June, Nijmegen, The Netherlands.

White, M., \& Epston, D. (1990). Narrative means to therapeutic ends. New York: W. W. Norton, \& Company. 